\title{
PERANAN VARIASI TEKANAN PEMBAKARAN DIFUSI TERHADAP KARAKTERISTIK SPRAY DENGAN BAHAN BAKAR MINYAK KAPUK
}

\author{
Muhammat Firman Pratama Hokil \\ Teknik Mesin, Fakultas Teknik \\ Universitas Maarif Hasyim Latif, Sidoarjo, Indonesia \\ e-mail : m-firman-pratama@student.umaha.ac.id
}

\begin{abstract}
ABSTRAK
Di karnakan tingginya tingkat konsumsi masyarakat terhadap bahan bakar fosil yang tidak dapat di perbaruhi bayak ilmuan sedang gencar mencari tenaga alternatif yang dapat di perbaharui yaitu minyak nabati, salah satunya iala minyak biji kapuk yang pemanfaatan bijinya kurang baik, penelitian ini bertujuan sebagai alat alternatif untuk pengganti bahan bakar fosil dalam penelitian ini menggunakan metode pengujian pembakaran spray yang berdiameter nozzle $0,2 \mathrm{~mm}$ bertipe cone dengan cara memvariasikan tekanan 50 bar,75 bar,dan 100 bar pada minyak biji kapuk uji coba di lakukan berulangkali agar mendapatkan hasil maksimal pengujian sudut pancaran droplet diketahui jika di berikan peningkatan pada tekanan diameter sudut pancaran droplet semakin lebar begitu sebaliknya jika terjadi penurunan tekanannya sudut akan semaki kecil,pada spray nyala api saat pengujian peningkatan tekanan yang di berikan pada nozzle $0,2 \mathrm{~mm}$ menimbulkan panjang nyala api makin panjang dan terjadi flashback pada jarang $500 \mathrm{~mm}$ di krnakan peningkatan tekanan droplet yang di timbulkan semakin kecil begitupula sebaliknya.
\end{abstract}

Kata kunci: diameter droplet, minyak biji kapuk, nyala api, sudut spray

\section{PENDAHULUAN}

\section{Latar Belakang}

Seiring kemajuan jaman saat ini banyaknya konsumsi bbm yang mengakibatkan pemanasan global dan langkanya bahan bakar fosil banyak ilmuan yang berbondong - bondong untuk mencari bahan bakar alternatif yaitu bahan bakar nabati (bbn)

Berbagai macam bahan baku untuk membuat bahan bakar minyak nabati atau bahan bakar alternatif contoh tebuh, kelapa, jarak pagar, kedelai, biji kapok ,kelapa sawit, bunga matahari, dan beberapa jenis tumbuhan lainnya. Salah satu bahan potensial di karnakan masih

Banyak yg kurang memanfaatkannya dengan maksimal yaitu biji kapuk. Agar dapat menurunkan nilai sfc dan memperoleh hasil pembakaran yang sempurna supaya dapat menurunkan nilai sfc, diperlukan suatu treatment pada bahan bakar tersebut. Treatment yang baik untuk di lakukan terhadap minyak pada saat pembakaran yaitu dengan memanaskan minyak sampai suhu temperatur tertentu yang akan menyebabkan turunnya densitas dan viskositas pada bahan bakar tersebut sebelum dialirkan ke dalam pompa tekanan tinggi, sehingga jika pada saat diinjeksikan keruang bakar akan berbentuk butiran-butiran kabut bahan bakar yang lebih halus yang akan menyebabkan proses pencampuran bahan bakar dan udara menjadi lebih homogen.

\section{Rumusan Masalah}

Menurut penelitianvyang sudah di uraikan, berikut ini rumusan masalah yang bisa di identifikasi adalah sebagai berikut :

1. Bagaimana pengaruh variasi tekanan pada nozzel terhadap sudut spray.

2. Bagaimana pengaruh variasi tekanan pada nozzelterhadap diameter droplet.

3. Bagaimana pengaruh variasi tekanan pada nozzelterhadap jarak semburan.

4. Bagaimana pengaruh variasi tekanan pada nozzelterhadap bentuk nyala api.

\section{Batasan Masalah}

Untuk menjelaskan ruang lingkup masalah dan untuk mencapai tujuan, perlu di berikan batasan - batasan masalah, dimana batasan masalah ini di perlukan parameter untuk di jadikan acuan dalam pembahasan peniulisan. Berikut parameter - parameter tersebut:

1. Variasi tekanan 50, 70, 100 bar.

2. Mengunakan diameter lubang nozzle $0,2 \mathrm{~mm}$.

3. Panjang api diukur dari ujung yang paling dekat dengan nozzle.

4. Tekanan di dalam tabung bahan bakar 15 bar.

5. Tekanan di luar dianggap $1 \mathrm{~atm}$.

6. Temperatur minyak kapuk diabaikan.

7. Kajian terhadap aspek ekonomi, keselamatan tidak dilakuka 


\section{Tujuan}

Berdasarkan batasan masalah yang telah di tentukan, tujuan dari penelitian ini adalah:

1. mengetahui pengaruh variasi tekanan pada nozzel terhadap sudut spray.

2. Mengetahui nilai pengaruh variasi tekanan pada nozzel terhadap diameter droplet.

3. Mengetahui pengaruh variasi tekanan pada nozzel terhadap jarak semburan.

4. Mengetahui pengaruh variasi tekanan pada nozzel terhadap bentuk dan karakteristik nyala api.

\section{Manfaat}

Adapun manfaat yang di dapatkan dari penelitian ini adalah sebagai berikut:

1. Bagi ilmu pengetahuan Memberikan informasi terhadap energi baru khususnya minyak nabati sebagai pengalihan dari bahan bakar fosil ke minyak nabati.

2. Bagi lembaga akademik

Kususnya bagi universitas maarif hasyimlatif sebagai lembaga pendidikan formal yang dapat membantu memperkenalkan terhadap masyarakat.

3. Supaya dapat di jadikan informasi \& dapat di kembangkan lagi bagi mahasiswa dalam penyusunan tugas akhir.

4. Bagi penulis

Mengaplikasikan ilmu yang telah di peroleh selama kuliah yang berbentuk karya nyata dan penelitian yang di harapkan berguna untuk masyarakat.

\section{METODE PENELITIAN}

\subsection{Flow chart}

Dalam proses dalam penelitian ini di butuhkan sistematika penyelesaian yang baik untuk mempermudah pengerjaan perencanaan. Penelitian tersebut di lihat pada uraian flowchart di bawa ini :

Berikut penelitian ini akan mengunakan metode experimental pada bahan yang akan di gunakan penelitian adalah minyak biji kapuk dengan alat simulasi seperti pembakaran pada mesin diesel. Alat yang akan digunakan adalah pompa bertekanan 150 bar di sambung ke selang menuju pressure lalu ke diameter lubang nozzle ditaruh pada dudukan meja instalasi berikut adallah gambar instalasi tersebut.

\subsection{Bahan}

Bahan - bahan yang di perlukan dalam melakukan penelitian ini yaitu minyak biji kapuk murni.

\subsection{Metode}

Siapkan minyak biji kapuk untuk di taru ke ember, siapkan nozzle berdiameter lubang $0,2 \mathrm{~mm}$, lalu mesin jet cleaner bertekanan tinggi 150 bar setel setel tekanan yang di perlukan untuk bahan penelitian yaitu
50 bar, 70 bar, 100 bar setelah itu di lakukan pengambilan vidio untuk dapat di ambil gambar agar bisa mengetahui sudut spray pada nozzle, panjang semburan api dan flashback yang terjadi.

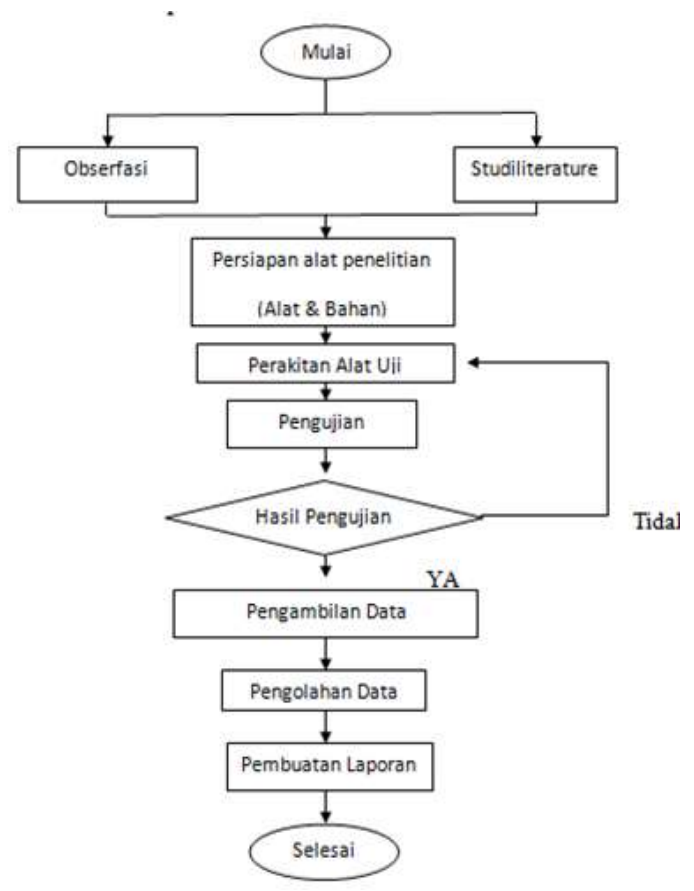

Gambar 1. Alur Penelitian

HASIL DAN PEMBAHASAN

\subsection{Data Perhitungan Kecepatan injeksi bahan bakar}

Kecepatan semburan bahan bakar dapat diperkirakan secara teoritis menggunakan rumus persamaan sebagai berikut (Liguang, 2007).

$$
\begin{aligned}
& \mathrm{V}_{\mathrm{inj}} 1=\mathrm{C}_{\mathrm{d}} \sqrt{\frac{2 . \Delta p i}{\rho l}} \\
& \text { Dimana : } \\
& \mathrm{C}_{\mathrm{d}} \quad=0,70 \text { (asumsi) } \\
& \rho_{\mathrm{L}} \quad=974 \mathrm{Kg} / \mathrm{m}^{2} \\
& \Delta \mathrm{p}_{\mathrm{inj}} 1=50 \mathrm{Bar}=5.000 .000 \mathrm{~kg} / \mathrm{ms}^{2} \\
& =5.10^{6} \mathrm{~kg} / \mathrm{ms}^{2} \\
& \Delta \mathrm{p}_{\mathrm{inj}} 2=75 \mathrm{Bar}=7.500 .000 \mathrm{~kg} / \mathrm{ms}^{2} \\
& =75.10^{5} \mathrm{~kg} / \mathrm{ms}^{2} \\
& \Delta \mathrm{p}_{\mathrm{inj}} 3=100 \mathrm{Bar}=10.000 .000 \mathrm{~kg} / \mathrm{ms}^{2} \\
& =10.10^{6} \mathrm{~kg} / \mathrm{ms}^{2}
\end{aligned}
$$

maka hasil dari perhitungan kecepatan bahan bakar minyak kapuk murni adalah : 


$$
\begin{aligned}
& v_{i} 1=C_{d} \sqrt{\frac{2 \Delta p_{i}}{\rho_{l}}} \\
& =0,70 \sqrt{\frac{2 \times 5 \times 10^{6} \mathrm{~kg} / \mathrm{ms}^{2}}{974 \mathrm{~kg} / \mathrm{m}^{3}}}=709,24 \mathrm{~m} / \mathrm{s} \\
& v_{i} 2=C_{d} \sqrt{\frac{2 \Delta p_{i}}{\rho_{l}}} \\
& =0,70 \sqrt{\frac{2 \times 75 \times 10^{5} \mathrm{~kg} / \mathrm{ms}^{2}}{974 \mathrm{~kg} / \mathrm{m}^{3}}}=86,863 \mathrm{~m} / \mathrm{s} \\
& v_{i} 3=C_{d} \sqrt{\frac{2 \Delta p_{i}}{\rho_{l}}}=100,303 \mathrm{~m} / \mathrm{s} \\
& =0,70 \sqrt{\frac{2 \times 10 \times 10^{6} \mathrm{~kg} / \mathrm{ms}^{2}}{974 \mathrm{~kg} / \mathrm{m}^{3}}}
\end{aligned}
$$

Menurut perhitungan secara teoritis kecepatan semprotan terhadap masing - masing variasi tekanan terhadap nozzle $0,2 \mathrm{~mm}$ yaitu $(709,24 \mathrm{~m} / \mathrm{s} ; 86,863 \mathrm{~m} / \mathrm{s}$; $100,303 \mathrm{~m} / \mathrm{s}$ ) dengan menggunakan diameter nozzle yang sama.

\subsection{Data Perhitungan Debit Bahan Bakar}

Karna masing - masing kecepatan semprotan bahan bakar pada tekanan yang berbeda - beda di ketahui secara teoritis maka cara untuk mengetahui hasil debit bahan bakar dapat di tentukan menggunakan rumus persamaan berikut:

$$
\begin{aligned}
& Q \quad=A \cdot V \\
& \text { Dimana: } \\
& A=\frac{\pi}{4} \cdot d^{2} \\
& A=\frac{3,14}{4} \cdot(0,2)^{2} \\
& A=0,031 \mathrm{~m}^{2}
\end{aligned}
$$

Hasil kecepatan semprotan yang di ketahui yakni

$$
\begin{array}{ll}
V_{\text {inj }} & 1=70,924 \mathrm{~m} / \mathrm{s} \\
V_{\text {inj }} & 2=86,863 \mathrm{~m} / \mathrm{s} \\
V_{\text {inj }} & 3=100,303 \mathrm{~m} / \mathrm{s}
\end{array}
$$

Sehingga nilai dari debit bahan bakar pada nozzel $0,2 \mathrm{~mm}$

$$
\begin{aligned}
\text { Q1 } & =\text { A.v } \\
& =0,000000031 \mathrm{~m}^{2} \cdot 70,924 \mathrm{~m} / \mathrm{s} \\
& =2,1986 \cdot 10^{-6} \mathrm{~m} 3 / \mathrm{s} \\
\text { Q2 } & =\text { A.v } \\
& =0,00000031 \mathrm{~m}^{2} \cdot 86,863 \mathrm{~m} / \mathrm{s} \\
& =2,6928 \cdot 10^{-6} \mathrm{~m}^{3} / \mathrm{s} \\
\text { Q3 } & =\text { A.v } \\
& =0,000000031 \mathrm{~m}^{2} \cdot 100,303 \mathrm{~m} / \mathrm{s} \\
& =3,1094 \cdot 10^{-6} \mathrm{~m}^{3} / \mathrm{s}
\end{aligned}
$$

Dalam penelitian ini tekanan yang divvariasikanvterhadap nozzle berdiameter tetap. Menurut perhitungan secara teoritis akan terjadi peningkatan debit bahan bakar pada saat tekanan terhadap nozzle diperbesar

\subsection{Hitungan Diameter Droplet}

Untuk mendapatkan hasil dari butiran droplet yang terbentuk hasil dari atomisasi bahan bakar dapat diperkirakan menggunakan persamaan Sauter Mean Diameter atau $\mathrm{D}_{32}$ berikut:

$\mathrm{D}_{32} 4.12 \mathrm{~d}_{\mathrm{n}} R e^{0,12} W e^{-0,75}\left\{\frac{\mu_{f}}{\mu_{a}}\right\}^{0,54}\left\{\frac{\rho_{f}}{\rho_{a}}\right\}^{0,18}$

Agar persamaan diatas bisa ditentukan nilainya maka harus ditentukan terlebih dahulu nilai Reynolds number (Re) spray dan Weber number (We) droplet. Dimana nilai Reynolds number dapat ditentukan menggunakan persamaan :

$$
\begin{aligned}
R e_{\text {sprayy }}=\frac{\mathrm{v}_{f} d_{n}}{v_{f}} & =\frac{70,924 \mathrm{~m} / \mathrm{s} \times 0,2 \mathrm{~mm}}{45.55 \mathrm{~mm}^{2} / \mathrm{s}} \\
& =311,411 \\
R e_{\text {sprayy }}=\frac{\mathrm{v}_{f} d_{n}}{v_{f}} & =\frac{86,863 \mathrm{~m} / \mathrm{s} \times 0,2 \mathrm{~mm}}{45.55 \mathrm{~mm}^{2} / \mathrm{s}} \\
& =381,396 \\
R e_{\text {sprayy }}=\frac{\mathrm{v}_{f} d_{n}}{v_{f}} & =\frac{100,303 \mathrm{~m} / \mathrm{s} \times 0,2 \mathrm{~mm}}{45.55 \mathrm{~mm}^{2} / \mathrm{s}} \\
& =440,40
\end{aligned}
$$

Sedangkan nilai Weber number dapat ditentukan menggunakan rumus persamaan :

$$
\begin{aligned}
& \begin{aligned}
W e_{\text {drop }}=\frac{\rho_{f} \mathrm{v}_{l}^{2} d_{n}}{\sigma_{l}} & \\
& =\frac{974 \mathrm{~kg} / \mathrm{m}^{3}(70,924 \mathrm{~m} / \mathrm{s})^{2} 0,2 \mathrm{~mm}}{34 \mathrm{~N} / \mathrm{m}} \\
& =28820 \\
W e_{\text {drop }}=\frac{\rho_{f} \mathrm{v}_{l}^{2} d_{n}}{\sigma_{l}} & \\
& =\frac{974 \mathrm{~kg} / \mathrm{m}^{3}(86,863 \mathrm{~m} / \mathrm{s})^{2} 0,2 \mathrm{~mm}}{34 \mathrm{~N} / \mathrm{m}} \\
& =43220
\end{aligned} \\
& W e_{\text {drop }}=\frac{\rho_{f} \mathrm{v}_{l}^{2} d_{n}}{\sigma_{l}} \\
& =\frac{974 \mathrm{~kg} / \mathrm{m}^{3}(100,303 \mathrm{~m} / \mathrm{s})^{2} 0,2 \mathrm{~mm}}{34 \mathrm{~N} / \mathrm{m}}=57640
\end{aligned}
$$

Dimana:

$\sigma_{f}($ teganganpermukaan $)=34 \mathrm{~N} / \mathrm{m}$ 
$\rho_{f}$ (berat jenis $)=947 \mathrm{~kg} / \mathrm{m}^{3}$

$\rho_{a}$ (row udara $)=1,2 \mathrm{~kg} / \mathrm{m}^{3}$

$v_{f}$ (viskositas) $=45,55 \mathrm{~mm}^{2} / \mathrm{s}$

$\mathrm{v}_{f}($ kecepatan inject $)=65,85 \mathrm{~m} / \mathrm{s}$

$\mathrm{d}_{\mathrm{n}}$ (diameter nozzle $)=0,2 \mathrm{~mm}$

$\mu_{f}$ (viskositas bahan bakar $)=28 \mathrm{Ns} / \mathrm{m}^{2}$

$\mu_{a}$ (viskositas udara $) \quad=0,89 \mathrm{Ns} / \mathrm{m}^{2}$

Karena nilai Reynolds number dan weber number sudah duketahui maka untuk mencari dimensi droplet adalah : $D_{32}=4,12 \times 0,2 \mathrm{~mm}(311,411)^{0,12}(28820)^{-0,75}$

$\left\{\left(34 \mathrm{Ns} / \mathrm{m}^{\wedge} 2\right) /\left(0.89 \mathrm{Ns} / \mathrm{m}^{\wedge} 2\right)\right\}^{\wedge} 0,54\{(974 \mathrm{~kg}$

$$
\begin{aligned}
& \left.\left./ \mathrm{m}^{\wedge} 3\right) /\left(1,2 \mathrm{~kg} / \mathrm{m}^{\wedge} 3\right)\right\}^{\wedge} 0,18 \\
& \quad=0,017 \mathrm{~mm}
\end{aligned}
$$

$D_{32}=4,12 \times 0,2 \mathrm{~mm}(381,396)^{0,12}(43220)^{-0,75}$

$\left\{\left(34 \mathrm{Ns} / \mathrm{m}^{\wedge} 2\right) /\left(0.89 \mathrm{Ns} / \mathrm{m}^{\wedge} 2\right)\right\}^{\wedge} 0,54\{(974 \mathrm{~kg}$

$$
\begin{aligned}
& \left.\left./ \mathrm{m}^{\wedge} 3\right) /\left(1,2 \mathrm{~kg} / \mathrm{m}^{\wedge} 3\right)\right\}^{\wedge} 0,18 \\
& \quad=0,013 \mathrm{~mm}
\end{aligned}
$$

$D_{32}=4,12 \times 0,2 \mathrm{~mm}(440,4)^{0,12}(57640)^{-0,75}$

$\left\{\left(34 \mathrm{Ns} / \mathrm{m}^{\wedge} 2\right) /\left(0.89 \mathrm{Ns} / \mathrm{m}^{\wedge} 2\right)\right\}^{\wedge} 0,54\{(974 \mathrm{~kg}$

$$
\begin{aligned}
& \left.\left./ \mathrm{m}^{\wedge} 3\right) /\left(1,2 \mathrm{~kg} / \mathrm{m}^{\wedge} 3\right)\right\}^{\wedge} 0,18 \\
& \quad=0,0109 \mathrm{~mm}
\end{aligned}
$$

Tabel 1. Hasil dari perhitungan droplet

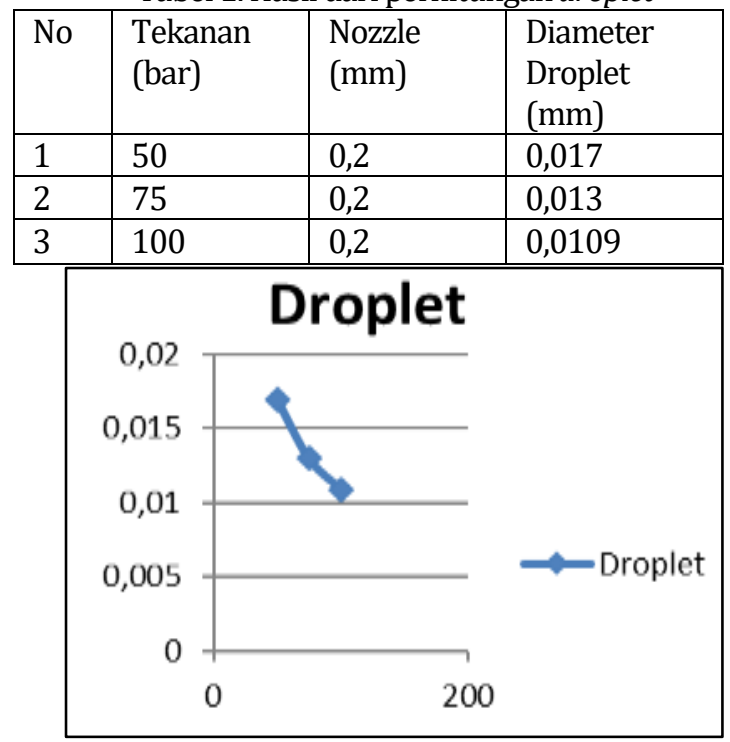

Gambar 1. Grafik diameter droplet

Semakin tinggi variasi tekanan yang di berikan, semakin kecil juga bentuk droplet yang di hasilkan seperti yang ada pada gambar grafik di atas tekanan 50 bar cenderung lebih besar dropletnya di bandingkan dengan tekanan 100 bar.

\subsection{Hubungan Variasi tekanan terhadap sudut spray}

\subsection{1 penjelasan secara teoritis}

Hasil perhitungan dari variasi tekanan 50 bar, 75 bar, dan 100 bar menggunakan diameter nozzle $0,2 \mathrm{~mm}$, minyakyang di gunakan untuk perhitungan minyak biji kapuk. Berikut perhitungan spray ialah :

$\theta_{1}=0,05\left(\frac{\Delta p i \cdot d^{2}}{\rho l \cdot \mu v}\right)^{1 / 4}$
Dimana

$$
\begin{aligned}
& \quad \Delta p_{i}=50 \mathrm{bar}=5 \times 10^{6} \mathrm{~kg} / \mathrm{ms}^{2} \\
& d^{2} \quad=0,2 \mathrm{~mm} \\
& \rho_{l}(\text { densitas })=974 \mathrm{~kg} / \mathrm{m}^{3} \\
& \mu v(\text { viscositas })=45,55 \mathrm{~mm}^{2} / \mathrm{s}
\end{aligned}
$$

Jadi nilai sudut dari minyak biji kapuk yang di berikan tekanan 50 bar ialah:

$$
\begin{aligned}
& \theta_{1}=0,05\left(\frac{\Delta p i \cdot d^{2}}{\rho l \cdot \mu v}\right)^{1 / 4} \\
& =0.05\left(\frac{5 \cdot 10^{6} \mathrm{~kg} / \mathrm{ms}^{2} \cdot(0,2 \mathrm{~mm})^{2}}{974 \mathrm{~kg} / \mathrm{m}^{3} \cdot\left(45,55 \mathrm{~mm}^{2} / \mathrm{s}\right)^{2}}\right)^{1 / 4} \\
& =0.05\left(\frac{5 \cdot 10^{6} \mathrm{~kg} / \mathrm{ms}^{2} \cdot(0,04 \mathrm{~mm})^{2}}{974 \mathrm{~kg} / \mathrm{m}^{3} \cdot\left(2074,8 \mathrm{~mm}^{2} / \mathrm{s}\right)^{2}}\right)^{1 / 4} \\
& =0.05\left(\frac{5 \cdot 10^{6} \mathrm{~kg} / \mathrm{ms}^{2} \cdot 4 \cdot 10^{-8} \mathrm{~m}^{2}}{974 \mathrm{~kg} / \mathrm{m}^{3} \cdot 2074 \cdot 10^{-12} \mathrm{~m}^{4} / \mathrm{s}^{2}}\right)^{1 / 4} \\
& =0.05\left(\frac{5.10^{6} \cdot 4 \cdot 10^{-8} \cdot 10^{12}}{974 \cdot 2074,8}\right)^{1 / 4} \\
& =0.05\left(\frac{20.10^{10}}{2020855,2}\right)^{1 / 4} \\
& =0,05(98968)^{1 / 4} \\
& =0,05 \cdot 17,736 \\
& \theta_{1}=0,886
\end{aligned}
$$

Jadi $\operatorname{arc} \tan 0,886=41,54^{0}$

Hasil perhitungan pada diameter nozzle $0,2 \mathrm{~mm}$ dengan tekanan 50 bar diketahui bahwa sudut spray sebesar $41,54^{\circ}$. Menurut perhitungan secara teoritis.

\subsubsection{Penjelasan secara eksperimen}

Berikut merupakan hasil pengujian secara eksperimen sudut spray dengan diameter lubang nozzle 0,2 mm dan variasi tekanan yang digunakan 50 bar, 75 bar, 100 bar.:

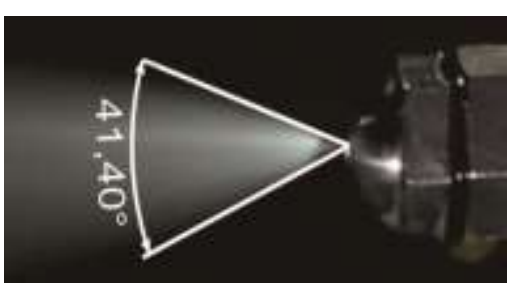

Gambar 2. Sudut tekanan 50 bar

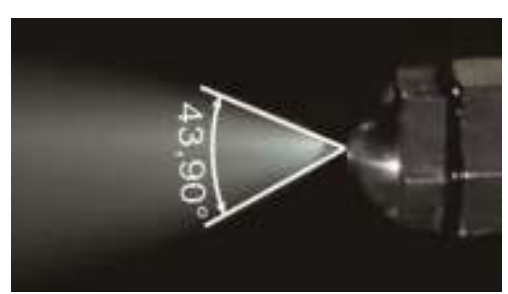

Gambar 3. Sudut tekanan 75 bar

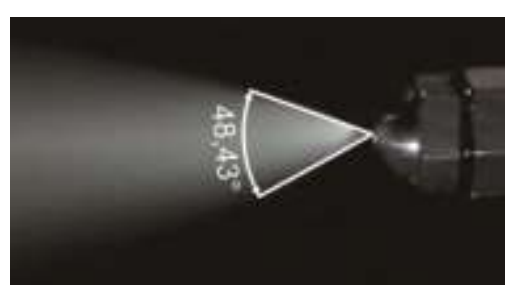

Gambar 4. Sudut tekanan 75 bar 
Hasil dari sudut spray tekanan 50 bar, 70 bar, dan 100 bar adalah $\left(41,40^{\circ} ; 43,90^{\circ} ; 48,43^{\circ}\right)$ di ketahui dari gambar di atas setiap di berikan peningkatan pada tekanan sudut spray yang di hasilkan semakin naik.

Tabel 2. Sudut spray

\begin{tabular}{|c|c|c|}
\hline NO & Variasi tekanan & Sudut \\
\hline 1 & 50 bar & $41,40^{0}$ \\
\hline 2 & 75 bar & $43,90^{0}$ \\
\hline 3 & $100 \mathrm{bar}$ & $48,43^{0}$ \\
\hline
\end{tabular}

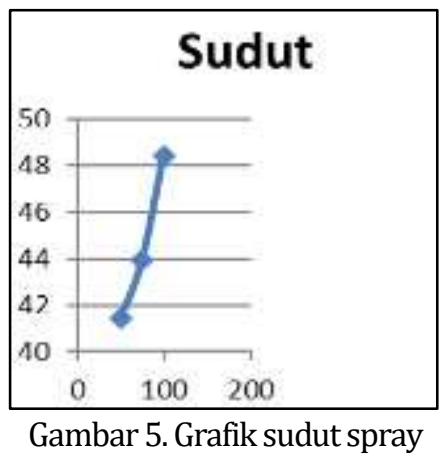

Seperti yang terlihat grafik gambar 5. Terdapat peningkatan sudut spray di setiap kali di berikan peningkatan pada tekanan

\subsection{Panjang nyala api}

Berikut Hasil pengujian panjang nyala api lubang nozzle 0,2 mm minyak kapuk ketika diberikan variasi tekanan 50 bar, 75 bar, dan 100 bar:

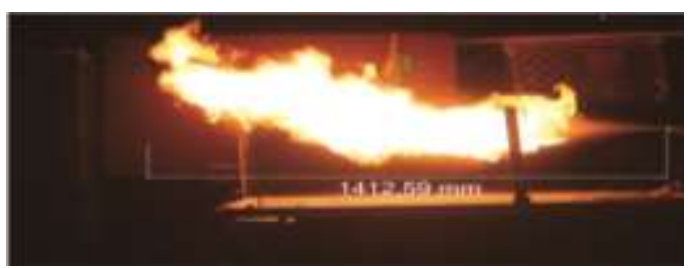

Gambar 6. Panjang nyala api tekanan 50 bar

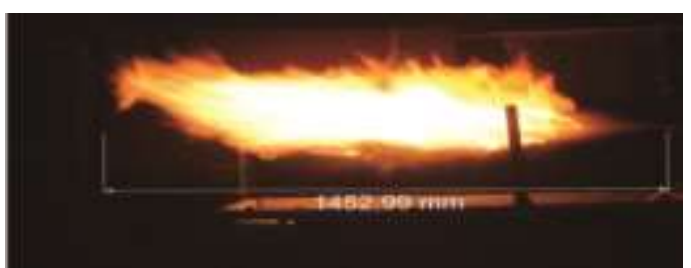

Gambar 7. Panjang nyala api tekanan 75 bar

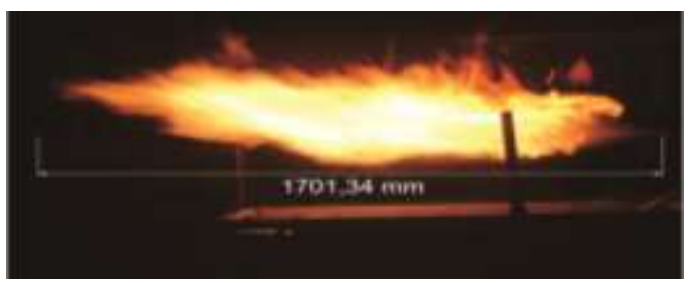

Gambar 8. Panjang nyala api tekanan 100 bar
Menurut hasil dari gambar di atas setiap peningkatan tekanan di berikan semakin panjang nyala api yang dapat di hasilkan terlihat perbedaan saat panjang api tekanan 50 bar dan 100 bar ada selisih jarak seklitar 288,75 mm.

Tabel 3. Panjang nyala api

\begin{tabular}{|l|l|l|}
\hline NO & Variasi Tekanan & $\begin{array}{l}\text { Panjang nyala } \\
\text { api }\end{array}$ \\
\hline 1 & 50 bar & $1412,59 \mathrm{~mm}$ \\
\hline 2 & 75 bar & $1452,99 \mathrm{~mm}$ \\
\hline 3 & 100 bar & $1701,34 \mathrm{~mm}$ \\
\hline
\end{tabular}

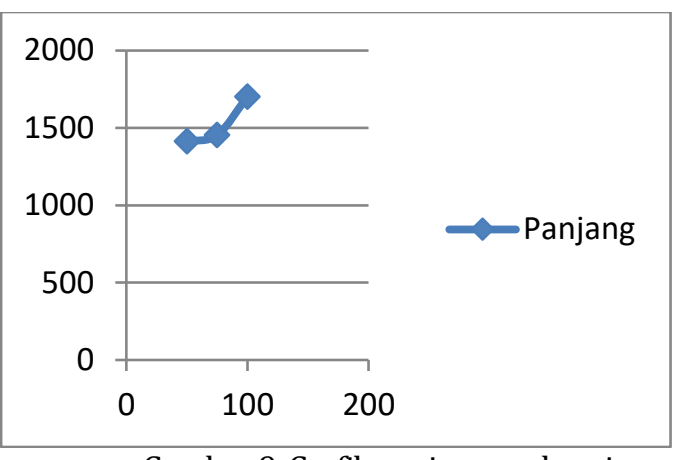

Gambar 9. Grafik panjang nyala api

Peningkatan tekanan yang di berikan 50 bar, 75 bar dan 100 bar. Jika di bandingkan dengan minyak biji kapuk murni yang di berikan variasi tekanan 50 bar dengan minyak biji kapuk murni yang di berikan variasi tekanan 100 bar, terjadi peningkatan panjang nyala api sebesar 288,75 mm, peningkatan jarak panjang api ini karnakan terjadinya penurunan tegangan minyak kapuk yang di sebabkan oleh peningkatan tekanan.

3.6 Hubungan variasi tekanan 50 bar, 75 bar, dan 100 bar nozzle 0,2mm terhadap flashback nyala api

\subsubsection{Flashback $100 \mathrm{~mm}$}
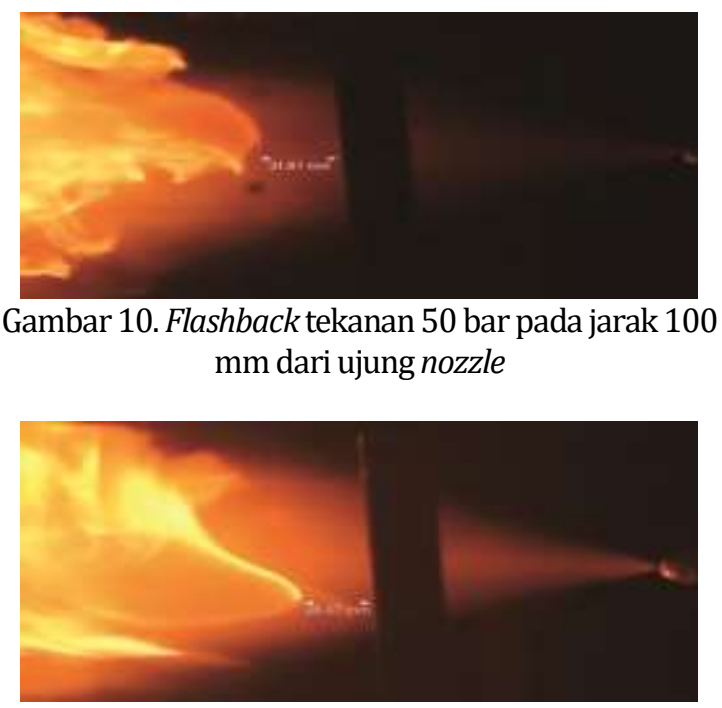

Gambar 11. Flashback tekanan 75 bar pada jarak 100 mm dari ujung nozzle 


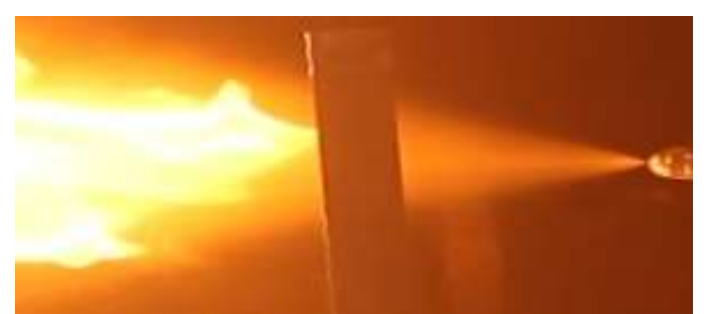

Gambar 12. Flashback tekanan 100 bar pada jarak 100 mm dari ujung nozzle

Pada gambar di atas menunjukkan bahwa tidak adanya terjadi flashback yang di hasilkan pada saat di berikan pemantik nyala api pada jarak $100 \mathrm{~mm}$ yang di tandai dengan adanya penggaris. Seperti pada gambar tekanan 50 bar dan 75 bar nyala api masih di belakang penggaris, pada tekanan 50 bar jarak di belakang penggaris masih 31,61 mm dan ketika di berikan peningkatan tekanan 75 bar nyala api masih ada di belakang penggaris tetapi jaraknya $26,47 \mathrm{~mm}$, lebih dekat dengan penggaris di bandingkan dengan tekanan 50 bar. Sedangkan pada saat di berikan peningkatan tekanan 100 bar di mana nyala api menempel pada penggaris dan tidak ada flashback yang terjadi.

\subsubsection{Flashback $500 \mathrm{~mm}$}

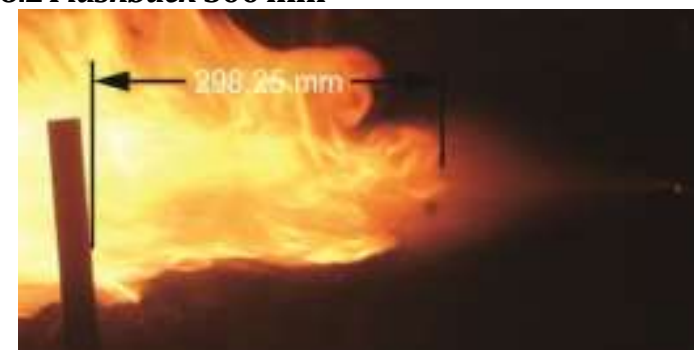

Gambar 13. Flashback tekanan 50 bar jarak $500 \mathrm{~mm}$ dari ujung nozzle

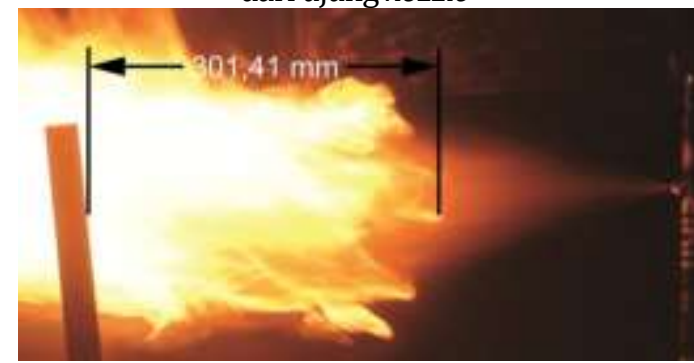

Gambar 14. Flashback tekanan 75 bar jarak 500 mm dari ujung nozzle

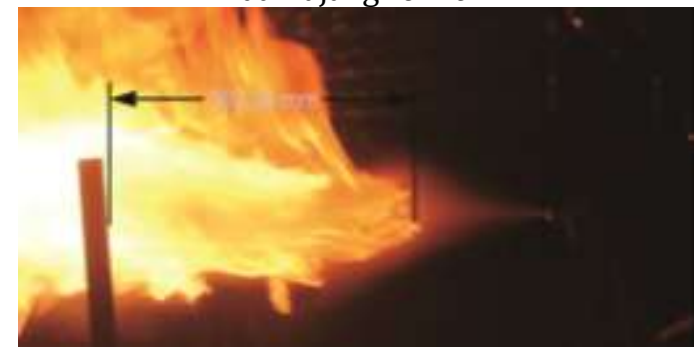

Gambar 15. Flashback tekanan 100 bar jarak 500 mm dari ujung nozzle

Pada gambar di atas menunjukkan bahwa adanya flashback yang terjadi pada jarak pemantik 500 mm yang telah di beri tanda dengan adanya penggaris seperti pada gambar di atas. pada variasi tekanan 50 bar nyala api 298,95 mm berada di depan penggaris, pada saat di berikan peningkatan variasi tekanan sebesar 75 bar terjadi peningkatan jarak terhadap nyala api 2,46 mm. Sedangkan setelah di berikan peningkatan variasi tekanan sebesar 75 bar nyala api yang terjadi lebih mendekat ke arah nozzle pada posisi 301,41 mm di depan penggaris. Pada jarak pemantik api yang terlihat pada gambar di atas yg berjarak $500 \mathrm{~mm}$ dari ujung nozzle terjadi flashback yang cukup panjang. Saat tekanan terhadap nozzle sebesar 50 bar terjadi flashback sepanjang 298,95 mm semakin di berikan peningkatan tekanan semakin nyala api mendekat ke nozzle ini di karnakan droplet yang telah terbentuk dengan sempurna di jarak 500

mm yang mengakibatkan terjadinya flashback yang cukup panjang

\subsubsection{Nyala api flashbackpada jarak $900 \mathrm{~mm}$}

Pada gambar di bawa ini menunjukkan hasil flashback jarak 900 mm yang di berikan variasi tekanan sebesar 50 bar,75 bar, dan 100 bar :

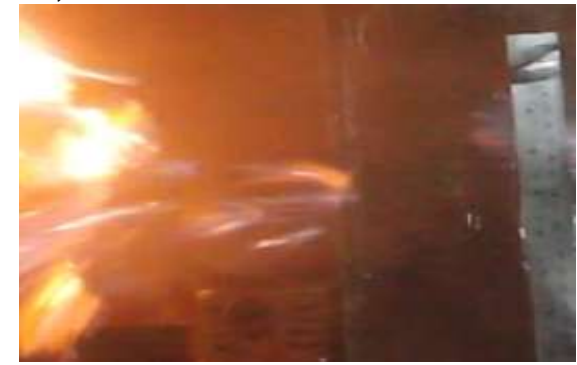

Gambar 16. Flashback jarak 900 mm tekanan 50 di hitung dari ujung nozzle

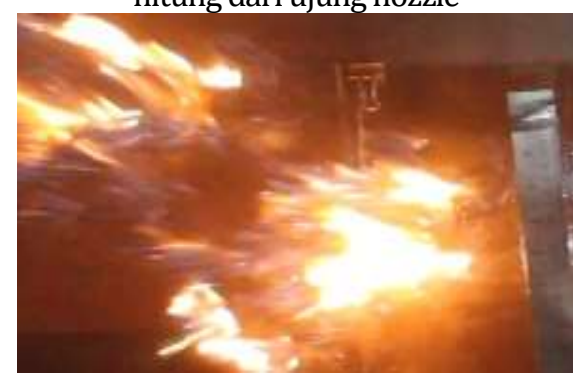

Gambar 17. Flashback jarak 900 mm tekanan 75 di hitung dari ujung nozzle

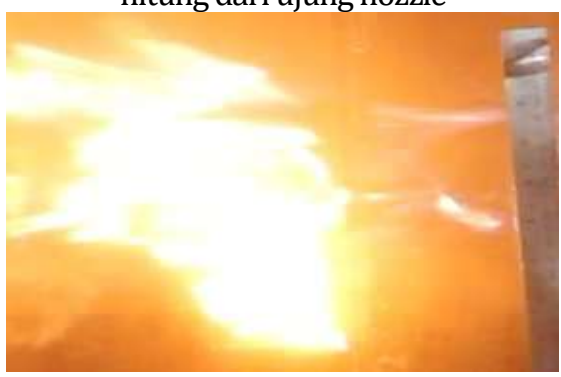

Gambar 18. Flashback jarak 900 mm tekanan 100 di hitung dari ujung nozzle

Di tunjukkan pada gambar di atas bahwa tidak ada flashback yang terjadi di jarak $900 \mathrm{~mm}$ hanya saja ada perbedaan ledakan nyala api yang terjadi di setiap 
tekanan makin tiggi tekanan yang di berikan makin tebal nyala api yang di hasilkan di akibatkan tekanan yang semakin besar.

\section{PENUTUP}

Hasil pengujian yang di dapatkan pada pengujian variasi tekanan pada nozzle

1. Tekanan berpengaruh pada besar sudut spray yang diperoleh jika di berikan tekanan rendah sudut spray akan semakin kecil sebaliknya jika di beri peningkatan pada tekanan sudut spray akan semakin tinggi.

2. Tekanan yang semakin besar akan membuat penurunan diameter droplet.

3. Tekanan sangat berpengaru terhadap jarak semburan api makin di berikan peningkatan tekanan makin panjang jarak semburan nyala api.

4. Tekanan berpengaruh pada panjang flashback nyala api jika di berikan peningkatan pada tekanan nyala api maka nyala api akan semakin mendekat ke arah ujung nozzle

\section{DAFTAR PUSTAKA}

Afifah, Y. N. (2016). ALIRAN TAK TUNAK FLUIDA NANO MAGNETOHIDRODINAMIK ( MHD) YANG MELEWATI BOLA.

Afifah, Y. N., \& Putra, B. C. (2018). Model Matematika Aliran Tak Tunak Pada Nano Fluid Melewati Bola Teriris Dengan Pengaruh Medan Magnet. Teknika: Engineering and Sains Journal, 2(2), 119-124.

Afifah, Y. N. (2019). Analysis of Unsteady Magneto Hydro Dynamic ( MHD ) Nano Fluid Flow Past A Sliced Sphere Analysis of Unsteady Magneto Hydro Dynamic ( MHD ) Nano Fluid Flow Past A Sliced Sphere. IOP Conference Series: Materials Science and Engineering, 494, 012033. https://doi.org/10.1088/1757899X/494/1/012033

Fajar, A. S., \& Hendrawati, T. Y. (2015). Proses Pengolahan Minyak Biji Kapuk ( Ceiba Pentandra ) Menjadi Methil Ester Melalui Proses Esterifikasi Katalis Koh Dan Waktu Reaksi. Teknik Kimia, (November), 1-9.

Hastono, A. D., Prasetyo, A., \& Mahmud, N. R. A. (2012). Penentuan Nilai Kalor Berbagai Komposisi Campuran Bahan Bakar Minyak Nabati. https://doi.org/10.18860/al.v0i0.1670

Gunawan, E. et al. (2019) 'Analysis of the Effect of Current Flow Variations in GTAW on SS 400 Plate Material Connected with SUS 304 Stainless Steel Plate Against Tensile Strength and Hardness with ER308L Electrodes',
Journal of Physics: Conference Series, 1175(1). doi: 10.1088/1742-6596/1175/1/012277.

Haryono \& Marlani. (2014). Salah satu sumber energi hayati potensial di indonesia adalah minyak biji kapuk (ceiba pentadra ). Minyak biji kapuk ini mengandung asam lemak tidak jenuh sekitar 63,27\%, dengan kadar asam lemak bebas sekitar 8,6\%.

I Wayan Suma Wibawa, Kusuma, I. G. B. W., \& Budiarsa, I. N. (2015). Uji Variasi Tekanan Nosel Terhadap Karakteristik Semprotan Bahan Bakar Biodiesel. 1(2), 35-44.

Juniarta, I. K., Wirawan, I. K. G., \& Ghurri, A. (2017). Studi Eksperimental Pengaruh Variasi Tekanan Terhadap Sudut Semburan Minyak Jelantah. 6(2), 2-6.

Kemajuan, L., Penelitian, H., \& Program, U. (2015). Pembentukan Spray Angle Minyak Nabati Pada Ujung Nosel.

Kustanto, M. N. (2017). Karakteristik Kecepatan Nyala dan Konsentrasi Ion pada Pembakaran Premixed Butana. Jurnal Rotor, 5(3), 28-31.

Yunita Nur Afifah, MNH Qomarudin and Imamatul Ummah (2020) 'Optimal Control Model Pemanenan Prey-Predator di Area Konservasi Ikan', Buana Matematika : Jurnal Ilmiah Matematika dan Pendidikan Matematika, 10(1), pp. 1-16. doi: 10.36456/buanamatematika.v10i1.2410. 
M Firman PH / Mechonversio, Vol. 2, No.1, Juni 2019, 49-56

Halaman ini sengaja dikosongkan 